\title{
In vivo cytogenetic effects of multiple doses of dietary vegetable oils
}

\author{
Cristina Márcia Wolf Evangelista ${ }^{1,3}$, Lusânia Maria Greggi Antunes ${ }^{1,2}$ and Maria de Lourdes Pires Bianchi ${ }^{1}$ \\ ${ }^{1}$ Departamento de Análises Clínicas, Toxicológicas e Bromatológicas, Faculdade de Ciências \\ Farmacêuticas de Ribeirão Preto, Universidade de São Paulo, Ribeirão Preto, SP, Brazil. \\ ${ }^{2}$ Departamento de Ciências Biológicas, Universidade Federal do Triângulo Mineiro, Uberaba, MG, Brazil. \\ ${ }^{3}$ Curso de Ciências Farmacêuticas, Universidade de Ribeirão Preto, Ribeirão Preto, SP, Brazil.
}

\begin{abstract}
Polyphenols are potent antioxidants that are particularly abundant in the Mediterranean diet, with olive oil being the main fat source. A number of investigations have reported that phenolic compounds found in dietary oils are antioxidants and could provide protective effects by inhibiting DNA oxidative damage. However, few studies have been published on the biological activity of vegetable oils, including their possible mutagenic/antimutagenic effects. The objective of the current study was to investigate the cytogenetic effects of multiple doses of four vegetable oils in rat bone marrow cells and to examine the possible antimutagenic effects of these oils in chromosomal damage induced by the antitumor drug cisplatin. These oils are consumed by humans and commonly used as drug vehicles. The rats received treatment with multiple doses of canola oil, olive oil, virgin olive oil, and corn oil (5 mL kg $\mathrm{kg}^{-1}$ alone or combined with the antitumor drug cisplatin $\left(5 \mathrm{mg} \mathrm{kg}^{-1}\right)$. Treatments with vegetable oils alone did not increase the percentage of cells with chromosomal aberrations $(p>0.05)$. Olive, virgin olive and canola oils showed protective effects against cisplatin-induced chromosomal damage $(p<0.05)$. A rational mechanism for the protective effects of vegetable oils is that their phenolic compounds have antioxidant and antimutagenic properties in vivo.
\end{abstract}

Key words: antimutagenesis, chromosomal aberrations, vegetable oils, Wistar rats.

Received: November 28, 2005; Accepted: June 1, 2006.

\section{Introduction}

Epidemiological studies have shown that populations consuming the traditional Mediterranean diet exhibit lower frequencies of chronic diseases and enjoy good health (Wahle et al., 2004). The Mediterranean diet, rich in fruits, vegetables, fish, wine and olive oil can contribute to a lower incidence of coronary heart disease and cancer (Tuck and Hayball, 2002).

Fruits, vegetables and polyphenols, potent antioxidants, are particularly abundant in the Mediterranean diet, with olive oil being the main fat source. A review concerning olive oil and breast and pancreatic cancer risk has demonstrated that increased dietary intake of olive oil is associated with a small decreased risk, or no increased risk of cancer. Data obtained with experimental animals suggests a tumor-inhibiting role for squalene, which is proposed as the most important factor in the cancer-risk reducing effect of olive oil (Newmark, 1999). A number of

Send correspondence to Lusânia Maria Greggi Antunes. Departamento de Análises Clínicas, Toxicológicas e Bromatológicas, Faculdade de Ciências Farmacêuticas de Ribeirão Preto Universidade de São Paulo, Av. do Café, s/n; 14040-903 Ribeirão Preto, SP, Brazil. E-mail: lusania@fcfrp.usp.br. investigations have reported that phenolic compounds, such as hydroxytyrosol, present predominantly in Olea europea, found in olive and virgin olive oils, are strong antioxidants and could provide protective effects by inhibiting oxidative damage (Tuck and Hayball, 2002). Cell culture experiments have demonstrated that olive oil phenolic compounds have anti-atherogenic and antioxidant effects, and could exert cardioprotective effects in vivo (Turner et al., 2005).

The effects of edible oils on hypertension and myocardial remodeling were investigated in spontaneously hypertensive rats. Canola oil and palm oil were effective in decreasing blood pressure, with greater cardiomyocyte vessel indices. Soybean oil and olive oil had mild effects on myocardial structure (Aguila et al., 2004). Recently, a potent antioxidant named canolol was isolated from crude canola oil and its potency was found to be greater than that of some well-known antioxidants, including $\alpha$-tocopherol, vitamin C and quercetin (Wakamatsu et al., 2005).

The investigation of the inter-relation between free radicals and antioxidant dietary oils is a field of great interest for elucidating mechanisms of mutagenesis/carcinogenesis (Owen et al., 2000). Previous studies have shown 
that the mutagenic activity of food mutagens can be modulated by vegetable oils (Perez et al., 2002). Kensese et al. (1989), observed weak mutagenic activity in several commercially edible palm and corn oils using liquid incubation bioassays with Salmonella typhimurium TA1537. Phenolic compounds present in virgin olive oil moderated the formation of carcinogenic/mutagenic heterocyclic amines in a model system (Monti et al., 2001). Seven vegetable oils consumed by humans were tested for genotoxic activity in the Drosophila somatic mutation and recombination test. Sunflower and olive oils gave inconclusive results, and virgin olive oil was clearly non-genotoxic (Rojas-Molina et al., 2005).

There is evidence in the literature suggesting that olive and canola oils have antimutagenic properties in animals (El-Nahas et al., 1993; Antunes and Takahashi, 1999; Evangelista et al., 2004). However, mutagenicity/antimutagenicity assays with dietary oils are limited to a few studies. The objective of the current study was to investigate the cytogenetic effects of multiple doses of four vegetable oils on rat bone-marrow cells and to examine the possible antimutagenic effects of these oils in chromosomal damage induced by the antitumor drug cisplatin. These oils are consumed by humans and commonly used as drug vehicles.

\section{Material and Methods}

\section{Chemical agents}

Commercially available oils, canola oil (CAO), olive oil (OLO), virgin olive oil (VOO), and corn oil (COO) were purchased in a local grocery store. Cisplatin (cDDP; cisdiamminedichloroplatinum II); CAS n. 15663-27-1, Platinil $^{\circledR}$ ) was obtained from Quiral Química do Brasil. All other chemicals and reagents used were of analytical grade.

\section{Chromosomal aberrations assay}

Healthy male and female Wistar rats were obtained from the Animal Center of the Prefeitura do Campus Administrativo de Ribeirão Preto (Universidade de São Paulo, Brazil). The rats were 6-7 weeks old and were housed in polycarbonate cages with steel wire tops. Animals weighed $100 \pm 5 \mathrm{~g}$ and were maintained at $23 \pm 2{ }^{\circ} \mathrm{C}$ in a controlled environment under a $12 \mathrm{~h}$ light/dark cycle and had free access to standard rat chow and fresh water ad libitum. This study was approved by the Animal Ethics Committee, Campus de Ribeirão Preto da Universidade de São Paulo, Brazil.

The rats were divided into experimental groups consisting of six animals, and negative and positive control groups. To assess the cytogenetic effects of multiple doses of dietary oils, the animals of the oil groups were treated with $\mathrm{CAO}, \mathrm{OLO}, \mathrm{VOO}$ or $\mathrm{COO}$ by gavage at a dose of $5 \mathrm{~mL} \mathrm{~kg}^{-1}$ b.w. $48 \mathrm{~h}, 24 \mathrm{~h}$ or $30 \mathrm{~min}$ before intra-peritoneal (i.p.) saline or cDDP. The dose of the oils tested was selected on the basis of preliminary results with single admin- istration (Evangelista et al., 2004). The dose of cDDP was the same as used by Antunes et al. (2000). In addition to these groups, one set of rats was treated with three administrations of distilled water and $5 \mathrm{mg} \mathrm{kg}^{-1}$ b.w. of cDDP i.p. alone and used as a positive control. A negative control group was treated with three administrations of distilled water and saline i.p. All animals were injected intraperitoneally with $4 \mathrm{mg} \mathrm{kg}^{-1}$ b.w. of colchicine (Sigma Chemical Co., St. Louis, MO, USA) 90 min. before euthanasia, which occurred $24 \mathrm{~h}$ after cDDP or saline administration.

For the analysis of chromosomal damage in metaphase cells, bone marrow preparations were prepared according to Preston et al. (1987) and the slides stained with Giemsa (Sigma Chemical Co., St. Louis, MO, USA). One hundred metaphase cells were scored per rat to determine total chromosomal aberrations and the mitotic index was obtained by counting the number of mitotic cells in 1000 cells per rat. The endpoints analyzed were mitotic index, total chromosome aberrations and percentage of cells with chromosomal aberrations. Only well-spread metaphases with $42 \pm 1$ chromosomes were randomly analyzed by light microscopy at 100x magnification. Chromosomal damage reduction percentages were calculated by comparing the treated groups with the group that received only the antitumor drug cisplatin.

\section{Statistical analysis}

The results were tabulated and experimental values expressed with \pm standard deviations (SD). One-way ANOVA was carried out and Student's t-test was used to detect significant differences amongst different treatment groups. The level of significance was $\mathrm{p}<0.05$. Gaps were not included in the statistical analysis.

\section{Results}

The cytogenetic analysis of bone-marrow cells from Wistar rats treated with dietary oils and cDDP revealed various types of chromosomal aberrations, which consisted of chromatid gaps, chromatid and chromosome breaks and exchanges. Chromatid and chromosome breaks were the most frequent type of aberrations. Chromatid gaps were not included in the total chromosomal aberrations or in the percentage of cells with aberrations. The results of the chromosomal aberrations test after multiple doses of CAO, OLO, $\mathrm{VOO}$, and $\mathrm{COO}$, alone or in combination with cDDP, are summarized in Tables 1 and 2. The frequencies of cells with chromosomal aberrations increased in the rats that received i.p. cDDP, and a statistically significant difference was observed for the negative control $(\mathrm{p}<0.05)$. The percentages of metaphases with aberrations in the groups treated with cDDP were 23.16, 21.66, 22.83, and $22.16 \%$. There was no significant difference between the group treated with dietary oils and the negative control regarding the induction of chromosomal damage $(\mathrm{p}>0.05)$. 
Multiple doses of dietary oils produced a statistically significant decrease in cDDP-induced chromosomal aberrations $(\mathrm{p}<0.05)$. Results shown in Table 1 indicate a $48.9 \%$ and $57.6 \%$ decrease of the cDDP-induced cells with aberrations when the animals were pre-treated with multiple doses of CAO or OLO, respectively. VOO was also efficient as a pre-treatment, resulting in a decrease of $54.7 \%$ of cells with aberrations, when compared with the group that received cDDP i.p. (Table 2). A reduction in chromosomal aberrations was registered in the group pre-treated with corn oil when compared with the group treated with cDDP, but the difference was not statistically significant $(\mathrm{p}>0.05)$.

The mitotic index evaluated as the percentage of dividing cells did not show any significant variation between treatments with the dietary oils and cDDP when compared with the negative control $(p>0.05)$. Mitotic indices of
4.3\% (CAO), 3.8\% (OLO), 4.1\% (VOO) and 4.2\% (COO) were recorded (Tables 1 and 2). This study implies that the administration of dietary oils does not have the potential to inhibiting the division of bone marrow cells.

\section{Discussion}

Toxicological data on dietary oils are scarce in the literature, and the potential involvement of corn oil gavage test-compound administration in unexpected carcinogenesis-toxicity testing has been reported (Landers et al., 1986). The guideline to conduct a scientifically valid in vivo chromosomal aberration bioassay recommended that the test substance, if insoluble in water or saline, should be dissolved or homogeneously suspended in vegetable oil (Tice et al., 1994). However, few studies have been published on the biological activity of vegetable oils including their possible mutagenic/antimutagenic effects, despite the

Table 1 - Mitotic index, and distribution of different types of chromosome aberrations, in bone marrow cells of Wistar rats pretreated with canola oil (CAO), olive oil (OLO), cisplatin (cDDP) and their respective controls.

\begin{tabular}{|c|c|c|c|c|c|c|c|c|}
\hline $\begin{array}{l}\text { Treatments } \\
\text { groups }\end{array}$ & $\begin{array}{c}\text { Mitotic index } \\
\%\end{array}$ & $\begin{array}{l}\text { Chromatid } \\
\text { gaps }\end{array}$ & $\begin{array}{c}\text { Chromatid } \\
\text { breaks }\end{array}$ & $\begin{array}{c}\text { Chromosome } \\
\text { breaks }\end{array}$ & $\begin{array}{c}\text { Chromosome } \\
\text { exchange }\end{array}$ & $\begin{array}{c}\text { Total } \\
\text { chromosomal } \\
\text { aberrations }\end{array}$ & $\begin{array}{c}\text { Cells with } \\
\text { chromosomal } \\
\text { aberrations \% }\end{array}$ & $\begin{array}{c}\text { Reduction } \\
\text { cells with } \\
\text { aberrations \% }\end{array}$ \\
\hline Control & 3.8 & 2 & 6 & 0 & 0 & 6 & $1.00 \pm 0.83$ & \\
\hline CAO & 4.3 & 2 & 7 & 1 & 0 & 8 & $1.33 \pm 1.14$ & \\
\hline cDDP & 3.5 & 4 & 131 & 14 & 3 & 148 & $23.16^{\mathrm{a}} \pm 6.22$ & \\
\hline $\mathrm{CAO}+\mathrm{cDDP}$ & 2.8 & 0 & 72 & 3 & 2 & 77 & $11.83^{\mathrm{a}, \mathrm{b}} \pm 3.96$ & 48.9 \\
\hline Control & 4.1 & 4 & 5 & 0 & 0 & 5 & $0.83 \pm 0.70$ & \\
\hline OLO & 3.8 & 3 & 11 & 0 & 0 & 11 & $1.66 \pm 1.22$ & \\
\hline cDDP & 3.7 & 15 & 124 & 10 & 3 & 137 & $21.66^{\mathrm{a}} \pm 10.21$ & \\
\hline $\mathrm{OLO}+\mathrm{cDDP}$ & 3.8 & 5 & 56 & 3 & 2 & 61 & $9.16^{\mathrm{a}, \mathrm{b}} \pm 3.76$ & 57.6 \\
\hline
\end{tabular}

Six-hundred cells were analyzed per treatment. Gaps were not included in the total and in the cells with chromosomal aberrations.

${ }^{a}$ Significantly different from negative control $(\mathrm{p}<0.05)$.

${ }^{\mathrm{b}}$ Significantly different from the cDDP group $(\mathrm{p}<0.05)$.

Table 2 - Mitotic index, and distribution of different types of chromosome aberrations, in bone marrow cells of Wistar rats pretreated with virgin olive oil (VOO) or corn oil (COO), Cisplatin (cDDP) and respective controls.

\begin{tabular}{|c|c|c|c|c|c|c|c|c|}
\hline $\begin{array}{l}\text { Treatment } \\
\text { groups }\end{array}$ & $\begin{array}{c}\text { Mitotic index } \\
\%\end{array}$ & $\begin{array}{l}\text { Chromatid } \\
\text { gaps }\end{array}$ & $\begin{array}{c}\text { Chromatid } \\
\text { breaks }\end{array}$ & $\begin{array}{c}\text { Chromosome } \\
\text { breaks }\end{array}$ & Exchange & $\begin{array}{c}\text { Total } \\
\text { chromosomal } \\
\text { aberrations }\end{array}$ & $\begin{array}{c}\text { Cells with } \\
\text { chromosomal } \\
\text { aberrations \% }\end{array}$ & $\begin{array}{c}\text { Reduction } \\
\text { cells with } \\
\text { aberrations \% }\end{array}$ \\
\hline Control & 4.0 & 1 & 6 & 0 & 0 & 6 & $1.00 \pm 0.63$ & \\
\hline VOO & 4.1 & 2 & 5 & 0 & 0 & 5 & $0.83 \pm 0.40$ & \\
\hline cDDP & 3.2 & 4 & 126 & 9 & 10 & 145 & $22.83^{\mathrm{a}} \pm 9.10$ & \\
\hline $\mathrm{VOO}+\mathrm{cDDP}$ & 3.5 & 9 & 62 & 0 & 1 & 63 & $10.33^{\mathrm{a}, \mathrm{b}} \pm 2.16$ & 54.7 \\
\hline Control & 4.4 & 2 & 6 & 1 & 1 & 8 & $1.33 \pm 1.03$ & \\
\hline $\mathrm{COO}$ & 4.2 & 0 & 6 & 0 & 0 & 6 & $1.00 \pm 0.63$ & \\
\hline $\mathrm{cDDP}$ & 3.7 & 5 & 147 & 13 & 2 & 162 & $22.16^{\mathrm{a}} \pm 4.87$ & \\
\hline $\mathrm{COO}+\mathrm{cDDP}$ & 3.9 & 2 & 104 & 6 & 9 & 119 & $15.66^{\mathrm{a}} \pm 6.50$ & 29.3 \\
\hline
\end{tabular}

Gaps were not included in the total and in the cells with chromosomal aberrations.

${ }^{a}$ Significantly different from negative control $(\mathrm{p}<0.05)$.

${ }^{\mathrm{b}}$ Significantly different from the cDDP group $(\mathrm{p}<0.05)$ 
beneficial properties of CAO, OLO and VOO on human health.

DNA damage is often measured as single-strand breaks, double-strand breaks or chromosomal aberrations, and increase in their frequencies is frequently associated with mutagenesis and carcinogenesis (Surh and Ferguson, 2003). In the present study, we investigated the cytogenetic effects of multiple doses of four dietary oils, and their association with the antitumor drug cDDP in rats using the chromosomal aberrations assay. The percentages of cells with chromosomal aberrations in the animals exposed to multiple doses of dietary oils were not statistically greater than those of the negative controls. A significant increase in the induction of chromosomal aberrations was observed in cDDP groups when compared with the oil groups and negative controls. Chromatid and chromosome breaks were the predominant types of damage induced by cDDP, and in general one aberration per cell was found. The cytogenetic effects caused by cDDP can be ascribed by the generation of reactive oxygen species.

cDDP is one of the most widely antineoplastic drugs used in the treatment of patients with a variety of malignancies. The generation of free radicals is believed to be an important mechanism in cDDP-induced mutagenicity, clastogenicity and toxicity (Wozniak et al., 2004). This antitumor drug is usually selected as a positive control for short-term antimutagenicity tests. Our data support the literature reports that show an increased frequency of chromosomal damage in rodent bone marrow cells after administrations of cDDP (Antunes et al. 2000; Mora et al., 2002).

The results demonstrated that the animals that received CAO, OLO, and VOO presented a marked statistically significant decrease in total chromosomal damage and in the percentage of cells with aberrations when compared with the cDDP group. The reduction in the percentage of cells with aberrations was $48.9 \%$ for $\mathrm{CAO}, 57.6 \%$ for OLO and $54.7 \%$ for VOO. The reduction produced by COO was $29.3 \%$, but it was not statistically significant. The exact mechanisms of the antimutagenic effects of vegetable oils are not well understood. In this study, the oils may have acted as an antioxidant by intercepting the free oxygen radicals generated by cDDP, since it is known that OLO and VOO are remarkably rich in effective phenolic antioxidants which could provide protection by inhibiting oxidative damage (Owen et al., 2000).

The antioxidant effects of OLO are probably ascribable to a combination of its high oleic acid content and its content of a variety of plant antioxidants, particularly oleuropein, hydroxytyrosol, tyrosol, and some minor components such as rutin, leuteolin and squalene (Visioli and Galli, 1998; Wahle et al., 2004). Manna et al. (2002) reported that the phenolic fraction extracted from VOO had a protective effect against the cytotoxic effects of reactive oxygen species in human erythrocytes and intestinal
Caco-2 cells. Hydroxytyrosol is a potent hydrogen peroxide scavenger and could be used as a possible chemoprotective agent in the metabolic pathways related to oxidative stress (O'Dowd et al., 2004). Antioxidant and antimutagenic activities of canolol, isolated from CAO, have been reported in the suppression of peroxynitriteinduced mutation in Salmonella typhimurium TA102 (Kuwahara et al., 2004).

Several polyphenols have been demonstrated to have clear antioxidant properties attributable to their free radical scavenging and metal chelating properties. It should be noted that polyphenols might exert other biological activities, such as effects on cell signaling pathways and on gene expression (Soobrattee et al., 2005). The COO, OLO, sesame, or soybean oils, commonly used as drug vehicles, may have different effects on specific hepatic CYP isoforms and may add to the variability in metabolism when xenobiotics are administered using dietary oils as drug vehicles (Brunner and Bai, 2000). Recent studies suggested that dietary polyphenols can stimulate the transcription of antioxidant and detoxification defense systems through antioxidant responsive elements, which are found in the promoters of many genes that may be induced by oxidative or chemical stress (Masella et al., 2005).

In our present study, the data obtained with multiple doses of CAO, OLO and VOO have shown that the dietary oils were neither cytotoxic nor mutagenic but had protective effects against cDDP-induced chromosomal aberrations in bone marrow cells. The OLO and VOO were the most effective in the inhibition of cytogenetic damage induced by the antitumor drug. Although $\mathrm{COO}$ was not mutagenic it failed to inhibit cDDP-induced chromosomal damage. These results suggested that phenolic compounds in corn oil may not have antioxidant effects. This could have benefits, since $\mathrm{COO}$ is the main vehicle usually used in mutagenicity assays.

Research on pharmacological intervention or diet is viable when based on risk/benefit analysis evaluating the efficacy and security of protecting agents in a variety of test systems, followed by clinical and epidemiological studies. Our results suggest that dietary oils might be useful for eventual therapeutic or dietary interventions.

\section{Acknowledgments}

The authors are grateful to Dr. Heloísa Della Coletta Francescato for the help and suggestions and to Mrs. Joana D'Arc C. Darin for the valuable technical assistance. This investigation was sponsored by the Brazilian agencies CAPES and CNPq.

\section{References}

Aguila MB, Sa Silva SP, Pinheiro AR and Mandarin-de-Lacerda CA (2004) Effects of long-term intake of edible oils on hypertension and myocardial and aortic remodelling in spontaneously hypertensive rats. J Hypertens 22:921-929. 
Antunes LMG and Takahashi CS (1999) Olive oil protects against chromosomal aberrations induced by doxorubicin in Wistar rat bone marrow cells. Genet Mol Biol 22:225-227.

Antunes LMG, Araújo MCP, Darin JDC and Bianchi MLP (2000) Effects of the antioxidants curcumin and vitamin $\mathrm{C}$ on cisplatin-induced clastogenesis in Wistar rat bone marrow cells. Mutat Res 465:131-137.

Brunner LJ and Bai S (2000) Effect of dietary oil intake on hepatic cytochrome P450 activity in the rat. Pharm Sci 89:10221027.

El-Nahas SM, Mattar FE and Mohamed AA (1993) Radioprotective effect of vitamins C and E. Mutat Res 301:143-147.

Evangelista CMW, Antunes LMG, Francescato HDC and Bianchi MLP (2004) Effects of the olive, extra virgin olive and canola oils on cisplatin-induced clastogenesis in Wistar rats. Food Chem Toxicol 42:1291-1297.

Kensese SM, Teng JI and Smith LL (1989) Mutagenic lipid peroxides from edible oils. Teratog Carcinog Mutagen 9:133145 .

Kuwahara H, Kanazawa A, Wakamatu D, Morimura S, Kida K, Akaike T and Maeda H (2004) Antioxidant and antimutagenic activites of 4-vinyl-2,6-dimethoxyphenol (canolol) isolated from canola oil. J Agric Food Chem 52:4380-4387.

Landers RE, Norvell MJ and Bieber MA (1986) Oil gavage test-compound administration effects in NTP carcinogenesis-toxicity testing. Prog Clin Biol Res 222:357-374.

Manna C, D'angelo S, Migliardi V, Loffredi E, Mazzoni O, Morrica P, Galletti P and Zappia V (2002) Protective effect of the phenolic fraction from virgin olive oils against oxidative stress in human cells. J Agric Food Chem 50:65216526.

Masella R, Di Benedetto R, Vari R, Filesi C and Giovannini C (2005) Novel mechanisms of natural antioxidant compounds in biological systems: Involvement of glutathione and glutathione-related enzymes. J Nutr Biochem 16:577586.

Monti SM, Ritieni A, Sacchi R, Skog K, Borgen E and Fogliano V (2001) Characterization of phenolic compounds in virgin olive oil and their effect on the formation of carcinogenic/ mutagenic heterocyclic amines in a model system. J Agric Food Chem 49:3969-3975.

Mora LO, Antunes LMG, Francescato HDC and Bianchi MLP (2002) The effects of oral glutamine on cisplatin-induced genotoxicity in Wistar rat bone marrow cells. Mutat Res 518:65-70.

Newmark HL (1999) Squalene, olive oil, and cancer risk. Review and hypothesis. Ann N Y Acad Sci 889:193-203.

O'Dowd Y, Driss F, Dang PM, Elbim C, Gougerot-Pocidalo M, Pasquier C and El-Benna J (2004) Antioxidant effect of hydroxytyrosol, a polyphenol from olive oil: Scavenging of hydrogen peroxide but not superoxide anion produced by human neutrophils. Biochem Pharmacol 68:2003-2008.

Owen RW, Giacosa A, Hull WE, Haubner R, Wurtele G, Spiegelhalder B and Bartsch H (2000) Olive-oil consumption and health: The possible role of antioxidants. Lancet Oncol $1: 107-112$.

Perez C, Lopez de Cerain A and Bello J (2002) Modulation of mutagenic activity in meat samples after deep-frying in vegetable oils. Mutagenesis 17:63-66.

Preston RJ, Dean BJ, Galloway S, Holden H, McFree AF and Shelby M (1987) Mammalian in vivo cytogenetic assays. Analysis of chromosome aberrations in bone marrow cells. Mutat Res 189:157-165.

Rojas-Molina M, Campos-Sanches J, Analla M, Munoz-Serrano A and Alonso-Moraga A (2005) Genotoxicity of vegetable cooking oils in the Drosophila wing spot test. Environ Mol Mutagen 45:90-95.

Soobrattee MA, Neergheen VS, Luximon-Ramma A, Aruoma OI and Bahorun T (2005) Phenolics as potential antioxidant therapeutic agents: Mechanism and actions. Mutat Res 579:200-213.

Surh Y-J and Ferguson LR (2003) Dietary and medicinal antimutagens and anticarcinogens: Molecular mechanisms and chemopreventive potential - Highlights of a symposium. Mutat Res 523:1-8.

Tice RR, Hayashi M, MacGregor JT, Anderson D, Blakey DH, Holden HE, Kirsh-Volders M, Oleson FB Jr, Pacchierotti F and Preston RJ (1994) Report from the working group on the in vivo mammalian bone marrow chromosomal aberration test. Mutat Res 312:305-12.

Tuck KL and Hayball PJ (2002) Major phenolic compounds in olive oil: Metabolism and health effects. J Nutr Biochem 13:636-644.

Turner R, Etienne N, Alonso MG, de Pascual-Teresa S, Minihane AM, Weinberg PD and Rimbach G (2005) Antioxidant and anti-atherogenic activities of olive oil phenolics. Int J Vitam Nutri Res 75:61-70.

Visioli F and Galli C (1998) Olive oil phenols and their potential effects on human health. J Agric Food Chem 46:4292-4296.

Wahle KW, Caruso D, Ochoa JJ and Quiles JL (2004) Olive oil and modulation of cell signaling in disease prevention. Lipids 39:1223-1231.

Wakamatsu D, Morimura S, Sawa T, Kida K, Nakai C and Maeda $\mathrm{H}$ (2005) Isolation, identification, and structure of a potent alkyl-peroxyl radical scavenger in crude canola oil, canolol. Biosci Biotechnol Biochem 69:1568-1574.

Wozniak K, Czechowska A and Blasiak J (2004) Cisplatinevoked fragmentation in normal and cancer cells and its modulation by free radical scavengers and the tyrosine kinase inhibitor STI571. Chem Biol Int 147:309-318. Associate Editor: Catarina S. Takahashi 